\title{
El populismo como relato y la crisis de la democracia representativa
}

\section{Populism as a narrative and the crisis of representative democracy}

\section{Camil Ungureanu}

Profesor agregado Serra Húnter de Filosofía Política, Departamento de Ciencias Políticas y Sociales, Universitat Pompeu Fabra. camil.ungureanu@upf.edu

\section{Ivan Serrano}

Profesor lector de Ciencia Política, Estudios de Derecho y Ciencias Políticas, Universitat Oberta de Catalunya. iserranoba@uoc.edu

Resumen: En este artículo se lleva a cabo un análisis crítico de algunas de las aproximaciones más influyentes al populismo actual y se propone una hipótesis alternativa. «Ontologizar» el populismo (Laclau), examinarlo desde una perspectiva fenomenológica (Canovan) u observarlo como una ideología (Freedon, Mudde, Stanley) son estrategias objetables por ser, desde nuestro punto de vista, demasiado intelectualistas. Aquí se propone, en cambio, una hipótesis de trabajo que considera el populismo como un relato político, poniendo el foco en la importancia de la imaginación y de las emociones políticas. Asimismo, se hace un repaso de las condiciones estructurales (sociopolíticas, económicas, tecnológicas, entre otras) de la oleada global de populismo y de su dificultad para superarlas.

Palabras clave: populismo, democracia representativa, capitalismo, emociones, política
Abstract: In this article a critical analysis is made of some of the most influential approaches to contemporary populism and an alternative hypothesis is proposed. "Ontologising" populism (Laclau), examining it from a phenomenological perspective (Canovan) and observing it as an ideology (Freedon, Mudde, Stanley) are objectionable strategies as they are, from our perspective, overly intellectualist. Instead, a working hypothesis is proposed here that considers populism as a political narrative, placing the focus on the importance of political emotions and imagination. An overview is also given of the structural conditions (sociopolitical, economic and technological, among others) of the global wave of populism and the problems it has overcoming them.

Key words: populism, representative democracy, capitalism, emotions, politics

Los autores (a su vez, coordinadores científicos del número 119 de Revista CIDOB d'Afers Internacionals sobre Populismo) agradecen a las editoras y a Eckart Woertz su apoyo y valiosos comentarios durante la realización de este proyecto. 
El populismo es un concepto esencialmente controvertido y se puede entender de varias maneras y con distintas metodologías (Ionescu y Gellner, 1969; Canovan, 1981 y 1982; Panizza, 2005; Mudde y Rovira Kaltwasser, 2011 y 2018; Müller, 2017; De la Torre, 2013 y 2017; Fassin, 2018). En este artículo se van a destacar tres aproximaciones al populismo actual por su influencia y representatividad: en primer lugar, la interpretación posestructuralista de Ernesto Laclau (1977, 2005a, 2005b y 2010), quien se acerca al populismo desde una perspectiva ontológica. Es la perspectiva teórica más ambiciosa desde el punto de vista filosófico y, además, ha tenido una influencia importante en diferentes movimientos políticos, especialmente en América Latina y España (Errejón y Serrano, 2011; Errejón et al., 2016; Laclau, 2005a; Iglesias, 2015; De la Torre, 2007 y 2013). En segundo lugar, la interpretación de Margaret Canovan

El populismo se puede analizar como un tipo de relato político constituido por patrones narrativos elementales (p. ej., el héroe salvador o el mundo decaído) que son politizados (p. ej., el pueblo como salvador), por vía de una lógica de exacerbación de las emociones políticas antagónicas.
(1981, 1982, 1999 y 2005), que rechaza la expectativa de una teoría general del populismo y propone una perspectiva fenomenológica, la cual genera una compleja e influyente tipología de populismos. Por último, y desde una aproximación más empírica, viene la interpretación del populismo como una ideología «delgada» (thin ideology) (Freeden, 1998; Mudde, 2004; Stanley, 2008) o un síndrome, y no como una doctrina (Wiles, 1969) ${ }^{1}$.

Desde nuestra perspectiva, estas aproximaciones serían objetables, ya que «ontologizar» el populismo (Laclau), analizarlo desde una perspectiva fenomenológica (Canovan) o examinarlo como una ideología (Freedon, Mudde, Stanley) son estrategias demasiado intelectualistas. En este artículo proponemos, en cambio, una hipótesis de trabajo que -complementando aproximaciones existentes- considera el populismo como un relato político, poniendo el foco en la importancia de la imaginación y de las emociones políticas. De esta manera, el populismo se puede analizar como un tipo de relato político ${ }^{2}$ constituido por patrones narrativos elementales (por ejemplo, el héroe salvador o el mundo decaído) que son politizados (por ejemplo, el pueblo como salvador), por vía de una lógica de exacerbación de las emociones políticas

1. Para un análisis más instructivo de varias posiciones sobre el populismo, véase Laclau (2005a).

2. Para la cuestión de los relatos en la política, véase en particular Lakoff (1996). 
antagónicas. Así, en primer lugar, se analizan brevemente las aproximaciones antes mencionadas del populismo; en segundo lugar, se desarrolla nuestra hipótesis de trabajo y, por último, se abordan los problemas y las condiciones estructurales del avance del populismo, recalcando las dificultades existentes para superarlos.

\section{Marco teórico y conceptual: sobre definiciones y metodologías}

En su aproximación, Ernesto Laclau (1977, 1980, 2005a, 2005b y 2010) propone una perspectiva ontológica y constructivista sobre el populismo nutrida por el posestructuralismo y la deconstrucción. En este sentido, y con respecto a las otras aproximaciones al populismo, pretende superar tanto el empirismo ad hoc (es decir, la perspectiva óntica) como la confusión entre lo empírico y lo normativo (Laclau, 2005a). Desde su perspectiva -una ontología que se propone explicar la construcción de las identidades colectivas-, el populismo no debe ser visto ni como un fenómeno político particular ni como algo negativo/positivo: el populismo se tiene que entender como parte de la respuesta a la pregunta respecto a la lógica de la formación de las identidades colectivas per se, independientemente de que sean democráticas, fascistas, nazis, etc. ${ }^{3}$. La dinámica populista emerge de las demandas sociales fragmentadas que no son satisfechas por las instituciones existentes. Dichas demandas no atendidas acaban articulándose, a pesar de su heterogeneidad, en lo que Laclau denomina unas «cadenas de equivalencia» (equivalential chains), y constituyen así una identidad (por ejemplo, de clase, nacional, popular, religiosa [ibídem: 74-75]). Esta identidad colectiva se construye en antagonismo con el poder hegemónico existente (por ejemplo, la élite o establishment) y con base en un «significante vacío» (empty signifier) (ibídem: 96-96) que subsuma las varias equivalencias. El significante vacío es a menudo un concepto clave (por ejemplo, pueblo, nación, clase, revolución) capaz de coagular mediante procesos discursivos retóricos demandas heterogéneas y equivalencias en un todo.

3. En el prólogo de La razón populista -su principal obra sobre el populismo- Laclau afirma: «Este libro se interroga centralmente sobre la lógica de la formación de las identidades colectivas» (Laclau, 2005a: ix). 
El enfoque original de Laclau ${ }^{4}$ tiene varios méritos, entre ellos, que es una contribución significativa a la ontología sociopolítica atenta, precisamente, al aspecto constructivo $^{5}$ de las identidades colectivas y al papel del conflicto y del discurso en la constitución de estas mismas; además, proporciona herramientas conceptuales útiles (como antagonismo, hegemonía, cadenas de equivalencia) para analizar la dinámica populista como una forma de antagonismo entre actores políticos colectivos que pueden tener ideas distintas o incluso opuestas (por ejemplo, de izquierdas o de derechas, progresistas o conservadoras, económicamente proteccionistas o liberales). Sin embargo, desde nuestro punto de vista, el tratamiento del populismo de Laclau no es del todo convincente, ya que toma un fenómeno circunscrito históricamente y lo convierte en una dimensión ontológica universal de la formación de cualquier identidad colectiva ${ }^{6}$. El «populismo ontológico» se convierte, así, en un concepto sobredimensionado incapaz de captar la especificidad del populismo como fenómeno moderno y la ola populista mundial actual (Canovan, 1999). Como sugiere su nombre, el «populismo» supone la creencia en el pueblo como fuente de legitimidad política ${ }^{7}$. Asimismo, como movimiento político moderno, está internamente vinculado al desarrollo gradual de la imaginación democrática centrada en el poder (kratos) del pueblo (demos) (ibídem). Según el influyente argumento de Reinhart Koselleck (1988), en las décadas alrededor de 1800 ocurrió una gran transformación del lenguaje político; en esa época, el horizonte de las expectativas políticas se alejaba del espacio de las experiencias que los seres humanos habían creado anteriormente; en particular, el futuro se convertía en un eje político-temporal fundamental durante el cual los pueblos ganarían su capacidad de autodeterminación y de referentes de la legitimidad política. Resulta que, si bien la cuestión ontológica de la formación de las identidades colectivas es legítima, la emergencia de la categoría del pueblo y del populismo como fenómenos históricos particulares no puede ser su clave explicativa universal. Además, Laclau (2005a) normaliza el antagonismo al tomar la confrontación con el enemigo inconmensu-

4. Un análisis más detallado de las complejidades de la visión de Laclau sobre el populismo y de su interpretación por parte de actores políticos provenientes de la academia (como Pablo Iglesias o Iñigo Errejón) está más allá del alcance de estas observaciones.

5. Nuestra posición no es completamente constructivista. Para la cuestión de los límites del constructivismo, véase más adelante la nota al pie número 17.

6. Para una crítica alternativa a esta afirmación, véanse especialmente Arditi (2010) y Bowman (2007).

7. Tal y como observa Canovan (1999: 3), el populismo es una «apelación al "pueblo" contra la estructura de poder establecida y las ideas y valores dominantes de la sociedad. Esta característica estructural determina el marco de legitimidad característico del populismo, su estilo político y su estado anímico [mood]». 
rable como «esencial» a la política ${ }^{8}$. Este enfoque sobre el antagonismo entre identidades colectivas inconmensurables puede llegar a la polarización y a la debilitación de la política democrática, la cual no está precisamente definida por el choque entre identidades separadas e inconmensurables, sino todo lo contrario, al implicar una identificación política transversal basada en principios, procedimientos y prácticas comunes de diálogo, compromiso y tolerancia.

La segunda aproximación al populismo, aunque tiene menos carga filosófica y creatividad conceptual que la anterior, gana en el análisis de la realidad empírica. Representada por Margaret Canovan (1981 y 1982), alerta de la excesiva expectativa respecto a la noción de populismo debido a la diversidad de contextos históricos y geográficos en la que surge. Según esta autora, la pretensión de llegar a construir una "teoría del populismo», aun siendo intuitivamente atractiva, está condenada a la inconcreción y la vaguedad. De hecho, rechaza una aproximación totalizante y esencialista del populismo por considerarla una manera demasiado rígida para abordar la diversidad de los casos particulares y las transformaciones prácticas. Así, opta por una aproximación fenomenológica y analiza los populismos en términos wittgensteinianos de «semejanzas de familia» (Familienähnlichkeiten) ${ }^{9}$. Esta aproximación tiene la virtud de prestar atención a la pluralidad histórica y contextual de los populismos (Canovan, 1982) a fin de elaborar tipologías orientadas a ser más consistentes, en vez de pretender llegar a una teoría con pretensiones de completitud. Sin embargo, el punto débil de este acercamiento es la adopción de criterios inconsistentes de clasificación entre populismos agrarios y populismos políticos ${ }^{10}$. Además, Canovan incluye fenómenos demasiados dispares bajo la etiqueta del populismo, como, por ejemplo, el narodniki $i^{11}$ ruso, el peronismo en Argentina, el crédito social en Alberta, los movimientos agrarios europeos después de la Primera

8. A pesar de la crítica tajante de Laclau (2005a) a la confusión entre lo normativo y lo empírico en los análisis del populismo, se puede argumentar que su teoría acaba casi amalgamando el antagonismo populista con su idea preferida de democracia radical.

9. Esta estrategia no busca un núcleo esencial de características ( $a, b, c)$ de un fenómeno, sino semejanzas de familia entre distintos fenómenos ordenados bajo el mismo concepto (a, b, c; b, c, d; c, d, a; d, e, f, etc.). Para una discusión aclaradora de la estrategia wittgensteiniana y su aplicación en el caso del fascismo, véase también Eco (1995).

10. Sobre esto, Laclau (2005a: 6) argumenta: «¿En qué sentido son los populismos agrarios no políticos? Y ¿cuál es la relación entre lo social y los aspectos políticos de los populismos "políticos" que generan un modelo de movilización política que es diferente del modelo agrario? Todo sucede como si Canovan simplemente hubiera elegido de manera impresionista características más visibles de una serie de movimientos tomados al azar (...)».

11. N. del Ed.: De narod, pueblo en ruso. Movimiento socialista ruso del siglo XIX que aspiraba a despertar políticamente a los campesinos y, con ello, lograr la liberalización del régimen zarista. 
Guerra Mundial, etc. Igualmente, en su versión inicial, su aproximación fenomenológica pierde de vista el análisis de los mecanismos de funcionamiento del populismo, así como de su relación con la democracia; aunque si bien es verdad que en sus textos posteriores pretende abordar estas problemáticas. En este sentido, la aproximación ulterior de Canovan (1999) resuena con la preocupación de la teoría política -desde Platón, con sus reflexiones sobre cómo degeneran los regímenes políticos hasta llegar a la tiranía, a Aristóteles, según el cual cada régimen ideal lleva consigo la semilla de su versión degenerada-. Así, se podría entender que el populismo es el resultado de las propias sombras de la democracia. La autora se apoya en la distinción que hace Michael Oakeshott (1996) entre la «política de la fe» y la "política del escepticismo»: la primera se mueve por un principio emancipador confiando en que se puede realizar su ideal; la segunda, en cambio, sospecha tanto de su entusiasmo como de su capacidad para conseguir dicho ideal. La democracia es, según Canovan (2005), una intersección entre ambas; lo que ella denomina la redención y el pragmatismo: una doble dimensión que se encuentra tanto en la idea de democracia -que a la vez plantea una especie de salvación a través de la políticacomo en su componente pragmático -cuyo objetivo es canalizar pacíficamente el conflicto a través de normas y prácticas-. También la noción de pueblo presenta esta doble dimensión, ya que contiene un componente redentor -si se entiende el poder popular como la única fuente legítima de autoridad-y un componente pragmático -que se centra en el papel de la democracia popular como manera de gestionar las comunidades políticas-. Es en la ambigüedad y las tensiones entre el componente inclusivo de la noción de pueblo -entendido como el conjunto de los miembros de una comunidad- y el componente exclusivo -el pueblo como la parte de la sociedad excluida del poder- donde detecta Canovan que se presenta la condición de posibilidad para el surgimiento de movimientos populistas (ibídem). Aunque este análisis más estructural de Canovan exagera la "predisposición mesiánica» de la democracia moderna -siguiendo el conservadurismo escéptico de Oakeshott-, se puede argumentar que su aproximación es un importante correctivo de la interpretación demasiado general de Laclau, quien pierde de vista tanto la relación interna como la tensión entre la democracia representativa y el antagonismo inherente al populismo.

Por último, la tercera aproximación, y que recientemente ha ido ganando más influencia en los estudios sobre el populismo, es la que representa Cass Mudde (2004 y 2007), la cual podemos ubicar en el ámbito de la ciencia política explicativa, a menudo con un fuerte componente cuantitativo. Desde una inicial aplicación a la aparición de los partidos de extrema derecha en Europa (ibídem), se ha ido extendiendo a otros casos para acabar definiéndose como una nueva ideología «delgada» (thin ideology), en la línea que anteriormente se había aplicado al nacionalismo, al feminismo o al ecologismo (Freeden, 
1998; Mudde y Rovira Kaltwasser, 2011; Stanley, 2008). Una de las características de las ideologías delgadas es la simplificación de los argumentos (también recalcada por Laclau) y la relevancia de ciertos conceptos claves, que en el caso del populismo acaban derivando en la contraposición entre dos bandos antagonistas, el pueblo y las élites. Según Mudde (2004: 543), el populismo es "una ideología que considera a la sociedad como dividida, en última instancia separada, en dos grupos homogéneos y antagonistas, "el pueblo puro" versus la "élite corrupta", y argumenta que la política debería ser una expresión de la volonté générale del pueblo» (Mudde, 2004; Mudde y Rovira Kaltwasser, 2011 y 2018). Desde esta aproximación, el populismo se caracteriza por su énfasis en el pueblo llano, que es excluido del poder aun cuando es no solo soberano y fuente última del poder, sino también debería constituirse como legítimo gobernante. En esta contraposición, la legitimidad del pueblo se expresa como la

voluntad general; y se constituye el Más allá de las aproximaciones distintas bien común como algo distinto a del populismo, hay un acuerdo respecto a la suma de intereses particulares, el cual debe ser el objeto de la actuación de las instituciones. El éxito del estudio del populismo desde la centralidad del antagonismo élite/pueblo y del carácter simplificador del discurso populista.

esta perspectiva ha llevado también, en una multitud de casos, a cuestionar cuáles deben ser sus límites para mantener una agenda de investigación futura que no desvirtúe el concepto (Mudde y Rovira Kaltwasser, 2018).

\section{Populismo como relato: una hipótesis de trabajo}

Más allá de las aproximaciones distintas del populismo, hay un acuerdo respecto a la centralidad del antagonismo élite/pueblo y del carácter simplificador del discurso populista. Sin embargo, a nuestro entender, el populismo visto como ontología o como una ideología son interpretaciones demasiado intelectualistas, ya que no confieren suficiente importancia a la centralidad de los patrones narrativos míticos ${ }^{12}$ ni a la lógica de las emociones "populistas».

12. Para la cuestión de los mitos en la política, véase especialmente Bottici (2010).

Revista CIDOB d'Afers Internacionals, n. 119, p. 13-33. Septiembre 2018 
Según la hipótesis de trabajo que se presenta en este artículo, el populismo es un relato que, a diferencia de las ideologías izquierdistas y derechistas en las democracias consolidadas, no está construido principalmente por una combinación de principios abstractos y de argumentos y propuestas de políticas públicas. Contrariamente, el relato populista está basado en figuras narrativas simples y accesibles, y en una dinámica emocional antagónica específica. Así, podemos caracterizar el relato populista como un tipo ideal (Max Weber) que intenta captar la especificidad de la oleada actual del populismo y la crisis de la democracia representativa. Se propone una aproximación ideal-típica y multidimensional al populismo que permita evitar una cierta tendencia -tanto en la academia como en la esfera pública- a pensar en él como un fenómeno dicotómico, debatiendo si ciertos movimientos políticos son o no son populistas.

Los rasgos o características del relato populista que se enumeran a continuación pueden ser realizados en parte y con distintas intensidades ${ }^{13}$; además, en la práctica, un líder o un partido político pueden adoptar una estrategia populista sin ser necesariamente populistas ${ }^{14}$.

\section{La construcción de la élite como enemigo}

El relato populista construye a las élites como homogéneas y las representa como la fuente del mal social y político. Escenificar a las élites como homogéneas se hace sobre la base de cadenas de equivalencias (Laclau, 2005a) entre individuos, grupos y sus agendas políticas, que de otro modo serían heterogéneos. En este escenario familiar, los miembros de la élite se convierten igualmente en traidores, ladrones, hipócritas y mafiosos. La élite constituye un sujeto colectivo: el villano que forja un mundo caído y corrupto. La élite corrupta no es solo nacional, sino que puede ser internacional (la burocracia europea) o incluso global (véanse las campañas contra el magnate y filántropo George Soros en Hungría o Rumania). Como consecuencia, el relato populista supone el rechazo radical del enemigo; un enemigo que debe ser encarcelado (lock her up!) o eliminado. En la metafórica de Trump, la élite ha convertido la sociedad en un "pantano»

13. Por ejemplo, Donald Trump se acerca mucho más al tipo de líder carismático que Pablo Iglesias (de Podemos), o una visión populista del pueblo puede ser más homogénea e intolerante que otra.

14. Un ejemplo de ello sería la construcción totalizante de la élite como corrupta por parte de Podemos en su fase inicial. 
(swamp) y será eliminada mediante un «drenaje» (drain). El populismo, dado que se nutre del antagonismo, tiene la predisposición de construir una variedad de enemigos según las circunstancias políticas y el contexto histórico (refugiados, inmigrantes, minorías sexuales, musulmanes, etc. $)^{15}$.

\section{La construcción antipluralista del pueblo}

Si el mundo es corrupto, se necesita un héroe o un salvador. El populismo imagina y construye a un pueblo homogéneo, incorrupto, bueno e incluso heroico (Müller, 2017) ${ }^{16}$. El pueblo es la víctima inocente de la élite y la fuente última de la legitimidad política y del bien en la sociedad. De nuevo, vemos cómo varias demandas heterogéneas se unen a través de una cadena de equivalencias (Laclau, 2005a) bajo el título del pueblo salvador y/o en oposición antagónica a la élite «antinacional» y a otros grupos de enemigos $^{17}$. La relación entre el pueblo y la élite es de antagonismo y violencia ( iencerradla!» ${ }^{18}$ gritaban los

\begin{abstract}
El populismo, dado que se nutre del antagonismo, tiene la predisposición de construir una variedad de enemigos según las circunstancias políticas y el contexto histórico (refugiados, inmigrantes, minorías sexuales, musulmanes, etc.)
\end{abstract}

15. El populismo es una fábrica permanente de enemigos. Por ejemplo, para Trump, el enemigo cambia de rostro de manera vertiginosa - puede ser Europa, Irán, China, Soros, los musulmanes, etc.-.

16. En este sentido, Müller subraya la concepción antipluralista del pueblo en la visión populista.

17. A diferencia de la posición de Laclau, nuestra aproximación no es puramente constructivista. El constructivismo puro o totalizante es anticientifico. Este constructivismo es un tipo de culturalismo («todo es construcción cultural») que ignora la contribución de la «naturaleza»y de las investigaciones científicas desde una perspectiva de la biología y psicología evolutiva. Según nuestra perspectiva, una explicación comprensiva debería combinar los dos aspectos, culturales y naturales, así como las disciplinas humanistas y científicas. Para un argumento respecto al populismo inspirado por la psicología evolucionista, véase Gros (2018). En el contexto de las manifestaciones violentas ultraderechistas de Chemnitz de septiembre de 2018, Gros argumenta que «la hostilidad hacia los extranjeros en el este de Alemania -y tal vez en toda Europa- puede estar enraizada en parte en una respuesta defensiva primordial por parte de los hombres locales, que quieren proteger su territorio, incluidas "sus" mujeres, de otros hombres. Probablemente no sea una coincidencia que Chemnitz, que ha demostrado estar dispuesto a votar por los partidos extremistas, tenga la mayor proporción de hombres por mujer entre los 20 y 40 años de toda Alemania» (ibídem).

18. Aquí interviene otro patrón mítico del chivo expiatorio: la comunidad se purifica mediante el sacrificio de un chivo expiatorio que condensa la impuridad y el mal (en este caso, Hillary Clinton como representante de la élite). Para un análisis de este mecanismo, véase Girard (1977). 
estadounidenses en los mítines electorales de Trump), en vez de intercambio de argumentos, deliberación y compromiso democrático.

Este relato populista se basa en la combinación de dos fuentes: por un lado, en patrones míticos-narrativos simples y emocionalmente sobrecargados (por ejemplo, el salvador/el héroe mítico, el mundo decaído o el mito del villano); por otro lado, estos patrones narrativos toman una forma política particularmente eficaz en tiempos de crisis social y frustración prolongada cuando se nutren de la imaginación democrática asentada en el conceptoimagen del pueblo (demos). El héroe salvador es el pueblo -o el líder emanado del pueblo- que lucha contra el mal representado por la élite y por otra minoría antipopular.

\section{El líder y la lógica de la emanación}

El populismo está generalmente caracterizado por la presencia de un líder fuerte (en general se trata de un hombre fuerte), carismático, o mesiánico, que expresa la voluntad del pueblo (Dragoman y Ungureanu, 2017). En contra de la élite hipócrita y mentirosa que se esconde detrás de la corrección política, el líder es valiente, sincero, capaz de desenmascarar con su straight talk a las élites. Ejemplos de tales líderes fuertes y carismáticos abundan: Donald Trump, Geert Wilders, Matteo Salvini, Recep Tayyip Erdoğan, Jean-Marie Le Pen, o Rodrigo Duterte. Según un patrón narrativo populista, el líder es un outsider, con respecto a la élite corrupta, o un hombre común, del pueblo, que se convierte milagrosamente en héroe y salvador. El líder-salvador tiene soluciones simples, inmediatas y radicales para convertir la sociedad corrupta y decaída en un lugar "de nuevo grande» (Make America Great Again).

El líder puede ser elegido según procedimientos democráticos, pero la relación con el electorado no es de representación mediada a través de la deliberación y de las reglas generales. La relación con el pueblo es más bien de emanación: el líder tiene un acceso personal, privilegiado e inmediato a los intereses del pueblo; el líder es la voz del pueblo. Según esta dinámica populista, el partido político se convierte en un accesorio al servicio del líder que se dirige directamente a las masas a través de Twitter, Facebook o la televisión. Asimismo, según la lógica de la emanación, el líder tiende a situarse por encima de los procedimientos democráticos y de las normas morales básicas de la interacción en la esfera pública (véase, por ejemplo, el uso de chistes e insultos racistas y sexistas por parte de Donald Trump, Nigel Farage, Boris Johnson, Beppe Grillo, Matteo Salvini o Rodrigo Duterte). 


\section{Intensificación de las emociones antagónicas}

La política supone -en contra del modelo racionalista deliberativo (Jürgen Habermas, John Rawls) - una dinámica de emociones y pasiones (Walzer, 2005). En cuanto a las emociones, el populismo no está a la par de las ideologías democráticas de izquierdas y derechas. Las emociones políticas tienen un papel primordial en el relato populista ${ }^{19}$; un relato que se construye con palabras e imágenes con un impacto emocional fuerte e inmediato, en detrimento de los argumentos, hechos y principios. Varios factores contribuyen a la primacía de las emociones fuertes en el populismo: en contraste con una ideología democrática habitual, el populismo es un llamamiento a la acción para enfrentarse al traidor y al enemigo; la propia lógica del populismo implica una exacerbación e intensificación emocional; ni los principios y valores abstractos, ni el debate detallado sobre políticas y hechos áridos le interesan al (líder) populista; por lo general, le inspira una narrativa simple sobre el bien y el mal, una narrativa inmediatamente accesible y emocionalmente cargada. El populismo reduce, como hemos subrayado, un espacio político complejo a una lucha bidi-

El populista usa el lenguaje emocional como un instrumento de poder y acción, como una forma de construir o fortalecer formas de identificación simbólico-afectiva con el pueblo y, al mismo tiempo, de dominación a través de la ira, la humillación y el desprecio hacia los demás. mensional entre el pueblo bueno y la élite mala; una simplificación generada por, y que a la vez produce, una intensificación de los sentimientos políticos antagónicos entre el pueblo y la élite. Además, la intensificación emocional inherente al populismo resulta de su horizonte temporal: el populismo es una política de la inmediatez, de mayor tensión y expectativas (casi)mesiánicas (Ungureanu y Dumitru, 2018).

El líder populista reemplaza la lógica democrática de la representación basada en reglas de juego y procedimientos impersonales por la de una identificación directa a nivel de emociones fuertes e imaginación. La identificación se manifiesta esencialmente a través de los aplausos y los gritos que se producen durante los

19. El papel de las emociones políticas en el populismo es mencionado por Laclau (2005a), Canovan (1999) y Mudde (2004). En la línea de Canovan, el populismo tiene mucho de un estilo particular de hacer política, así como de un "estado de ánimo" (mood), que incluye tanto un sentido de trascendencia contra el estado actual de la política como de apelación a elementos emocionales que caracterizan el zeitgeist populista (Mudde, 2004). 
mítines populares ${ }^{20}$; así, el populista usa el lenguaje emocional como un instrumento de poder y acción, como una forma de construir o fortalecer formas de identificación simbólico-afectiva con el pueblo y, al mismo tiempo, de dominación a través de la ira, la humillación y el desprecio hacia los demás (por ejemplo, las élites, los refugiados, los homosexuales, los musulmanes, etc.). Mediante un lenguaje racista y sexista, incluso utilizando el insulto, el líder populista activa el «cerebro emocional» (Ledoux, 1998) y atiza afectos negativos de ira, miedo y desprecio hacia los extranjeros y los enemigos del pueblo ${ }^{21}$. Además, las emociones como la ira y el miedo intensificadas por la lógica populista son emociones primordiales. Desde la perspectiva de la neurociencia y la biología evolucionista, las emociones primordiales son asociadas con las regiones bajas y antiguas del cerebro (Denton, 2006). De aquí la fuerza particular del relato populista que activa estas emociones ${ }^{22}$ y las grandes dificultades actuales de contrarrestarlo.

\section{El cuestionamiento de los mecanismos de la democracia representativa}

Esta caracterización ideal-típica tiene como corolario que el populismo mina los mecanismos de la democracia representativa ${ }^{23}$. Los populistas denuncian el fracaso de los mecanismos e instituciones tradicionales de la democracia representativa, tanto por sus propios límites como por la captura que las élites han hecho de los mismos. Los populistas cuestionan a menudo las reglas básicas del juego democrático y, a cambio, ofrecen soluciones mágicas a los problemas complejos de la sociedad, minando la práctica democrática basada en deliberación, negociación y

20. Para ilustrarlo, cabe mencionar que no es una casualidad que Trump organizara mítines electorales inmediatamente después de ganar las elecciones.

21. Podemos distinguir tres tipos de emociones populistas: a) emociones negativas, que se refieren a sentimientos de odio, resentimiento, furia, desprecio o ira hacia la élite, las minorías o a los extranjeros (el populismo de derechas, en particular, intensifica el desprecio, la humillación y el miedo); b) emociones con efectos positivos, que incluyen el entusiasmo por las utopías y las revoluciones, el orgullo popular-nacional, la esperanza mesiánica hacia el líder carismático, la confianza en las virtudes del pueblo (por ejemplo, el Make America Great Again); y c) emociones mixtas, como el disfrute rencoroso, la humillación jubilosa a los extraños y las minorías, o el placer vengativo.

22. Para un estudio reciento sobre el miedo y Trump, véase Nussbaum (2018).

23. La estrategia que presentamos no implica una confusión entre lo normativo y lo empírico; es decir, el tipo-ideal construye el populismo desde un interés normativo, pero esta es una práctica legítima en ciencias políticas y sociales. Por ejemplo, en ciencias políticas, la distinción entre regímenes autoritarios y democráticos no es ilegítima porque refleja un interés normativo. 
compromiso. El populismo es personalista e identitario; en cambio, la democracia representativa se basa en procedimientos impersonales y mecanismos de mediación. Desde esta perspectiva, hablar de populismo de izquierdas o de derechas no es incorrecto, pero puede ser engañoso: dada su fluidez, el populismo puede combinar ideas de derechas y de izquierdas ${ }^{24}$. En este sentido, las etiquetas se oscurecen en cuanto el populismo cuestiona y supera la dinámica tradicional del eje izquierda/ derecha que actuaba dentro de los parámetros de la democracia representativa.

Esta aproximación ideal-típica permite la clasificación de fenómenos empíricos según su acercamiento -en varios grados y con varias intensidades-a las características del populismo. En el caso de Podemos, por ejemplo, se encuentran elementos populistas antagonistas y, en cierta medida, un liderazgo relativamente personalista, aunque no mesiánico; sin embargo, este partido no tiene una visión antipluralista del pueblo, ni elude la complejidad de la práctica política, ni tampoco pone en cuestión los mecanismos de la democracia representativa. Es decir, aunque Podemos ha usado ciertas estrategias populistas, sería difícilmente calificable de plenamente populista, dado que unos de sus principales retos ha sido la recuperación de la representación democrática conectándola de nuevo con la participación ciudadana. Asimismo, el hecho de analizar a fondo otros casos recientes -como son la elección de Donald Trump en Estados Unidos, la campaña sobre el referéndum del Brexit en el Reino Unido o la emergencia de ciertos liderazgos en países como Italia, Filipinas, Venezuela o Hungría- nos permite observar cómo, aun cumpliendo con todos los elementos planteados anteriormente, el populismo se presenta en formas y combinaciones diversas ${ }^{25}$.

\section{Las crisis de la democracia representativa}

Si algo define el momento actual, más allá de la controversia entre diferentes perspectivas y aproximaciones metodológicas, es el contexto de la crisis de representación de las instituciones contemporáneas. Todo ello además ha surgido

24. Un buen ejemplo es el movimiento Cinque Stelle en Italia, el cual combina ideas izquierdistas y derechistas.

25. Los intentos de trazar cómo el populismo de los partidos de extrema derecha ha ido permeando en el discurso de los partidos tradicionales o las limitaciones para establecer actitudes populistas en la opinión pública -que permitan caracterizar adecuadamente si un determinado caso puede clasificarse como tal- continúan lejos de generar un consenso en la literatura (Akkerman et al., 2014; Hawkins et al., 2012; Tipaldou y Uba, 2018). 
en el marco de la llamada sociedad de la información -las redes sociales- y de la tensión estructural y creciente entre democracia y capitalismo. Ya sea la respuesta a las sombras que proyecta la misma democracia representativa -a la manera de Canovan-, el populismo puede desarrollarse como síntoma, reacción, factor de crisis y, a su vez, generar cambios y problemas estructurales en las democracias actuales ${ }^{26}$. En este sentido, podemos distinguir varios escenarios donde se han formado las condiciones estructurales favorables al populismo ${ }^{27}$.

En el ámbito de la política democrática, los partidos políticos tradicionales (de masa) jugaron siempre un rol clave en la estabilidad de las democracias representativas, al actuar como mecanismos de intermediación esenciales entre los ciudadanos y los estados-nación (Morlino, 2014; Linz y Stepan, 1996). Estos partidos, junto a otras instituciones y organizaciones relacionadas (como los sindicatos), conformaban una red de formación de la opinión y la voluntad política de los ciudadanos, asumiendo la representación de dichas ideas y voluntades en las instituciones representativas y ejecutivas. Además, los partidos tenían la función de formar a los líderes políticos, durante varios años de aprendizaje, como parte de una compleja maquinaria institucional. A nivel ideológico, los partidos tradicionales con un sólido arraigo en la sociedad se articulaban alrededor de ejes de competición política relativamente estables, principalmente en el eje izquierda-derecha, estructurando tanto los debates políticos como la agenda gubernamental. Así, los regímenes democráticos fueron estables en la medida en que los mecanismos de representación y de separación de poderes eran aceptados por los agentes políticos, hecho que garantizaba su continuidad y la alternancia política entre las distintas opciones ideológicas y los diferentes partidos, los cuales aceptaban y apoyaban las reglas del juego (Linz y Stepan, 1996).

En las últimas décadas, sin embargo, los partidos tradicionales de masa han ido perdiendo una parte significativa de su poder formativo y función representativa; ello ha sido así por varios factores, entre otros: la cartelización de los partidos y su pérdida de legitimidad frente a los ciudadanos, la creciente individualización del votante, los cambios ideológicos y la transformación de los medios de comunicación. En este contexto cambiante, han crecido los nuevos tipos de líderes populistas, quienes construyen su legitimidad apelando directamente al pueblo mediante los nuevos medios de comunicación, tendiendo a subordinar la maquinaria del partido a su persona e intereses. La crisis de los partidos tradicionales como mecanismos de intermediación y construcción de la representatividad

26. Véase también el reciente estudio empírico del Pew Research Centre (Stokes, 2018).

27. En la práctica, estos factores se mezclan y se retroalimentan. 
está conectada, asimismo, con un cambio ideológico importante derivado de la caída del muro de Berlín y del giro neoliberal de la izquierda europea. El eje ideológico izquierda-derecha, que articulaba la competición ideológica desde la Segunda Guerra Mundial, se ha tornado borroso o ha perdido la capacidad para encapsular los diferentes retos y alternativas políticas. En este contexto, los movimientos políticos populistas tienden a sujetar el eje izquierda-derecha en una lógica discursiva en la que se contrapone la oposición pueblo-élite, lo que les permite a menudo combinar planteamientos políticos dispares en términos izquierda-derecha dentro del mismo programa político.

Esta dinámica populista está, además, favorecida por la transformación estructural de los medios de comunicación. De manera tradicional, los periódicos jugaban un papel constitutivo en la formación de las opiniones ciudadanas y la estructuración del espacio público. Pero estos medios de comunicación han ido perdiendo su función de intermediación a favor de redes sociales como Facebook, Twitter o Instagram, cuyos mensajes forzosamente simplificados y cargados de emocionalidad y sensacionalismo tienen más peso que los argumentos y la complejidad fáctica. En la era de las redes sociales, la esfera pública se ha acelerado; se apela a la opinión pública con mensajes aparentemente simples, que provocan emociones fuertes y efímeras a fin de influenciar

El eje ideológico izquierda-derecha ha perdido la capacidad para encapsular los diferentes retos y alternativas políticas. En este contexto, los movimientos populistas tienden a sujetar el eje izquierda-derecha en una lógica discursiva en la que se contrapone la oposición pueblo-élite, lo que les permite a menudo combinar planteamientos políticos dispares en términos de izquierda-derecha.

y movilizar al electorado. La esfera pública se ha convertido así, en buena medida, en la arena de manipulación emocional y ficción, tal y como muestra la importancia de las denominadas fake news (noticias falsas) para la estrategia electoral y política $^{28}$. Como remarcaba Jonathan Swift (citado en Meyer, 2018), «[L]a Falsedad vuela, y la Verdad viene cojeando después» ${ }^{29}$. En un ambicioso estudio del MIT sobre la circulación de fake news en Twitter, publicado en Science, se argumenta que las noticias falsas se propagan de manera mucho más rápida y amplia que las

28. Un brillante episodio de 2013 de la serie creada por Charlie Brooker Black Mirror capta con humor negro esta situación y anticipa brillantemente el debate actual sobre el populismo y las fake news. En "El momento Waldo», un flamante personaje de dibujos animados (llamado Waldo) entra en campaña electoral y arrasa con chistes licenciosos e insultos direccionados a los políticos; después de su éxito electoral, Waldo se convierte en un fenómeno viral a nivel global.

29. Original: «Falsehood flies and the Truth comes limping after it». 
verdaderas, probablemente debido a su novedad y a su carga emocional (Vosoughi et al., 2018). De la misma manera, el populismo -como primacía de los afectos, ficciones y fake news sobre los argumentos y los hechos- emerge y crece usando la velocidad y la inmediatez de las nuevas tecnologías de la comunicación, y erosiona o al menos pone en cuestión las instituciones y mecanismos más lentos de intermediación esenciales para el funcionamiento de la democracia representativa.

A ello hay que sumarle, además, la tensión estructural y creciente entre el capitalismo corporativo y la democracia representativa. A nivel económico, el Estado-nación retenía, a través de sus recursos de poder y la cooperación con terceros estados en instituciones supranacionales, la capacidad regulatoria de los grupos de interés económico en el ámbito nacional. Fue un sistema que se mantuvo estable mientras fue capaz de proveer cierta redistribución económica que evitara las desigualdades extremas entre los ciudadanos del mismo Estado, así como una cierta perspectiva de estabilidad y progreso social y económico. Sin embargo, la globalización -acelerada desde la década de 1970 - ha ido erosionando gradualmente los vínculos entre los estados-nación, sus partidos y los grupos de interés. El aumento de la desigualdad que ha generado el capitalismo (Piketty, 2016) ha comportado, además, una creciente tensión entre el capitalismo y la política representativa. Tal y como ya argumentaba Aristóteles, una democracia constitucional en la que hay desigualdades económicas abismales entre su ciudadanía no es sostenible. El sueño neoliberal de la harmonía entre el capitalismo y la democracia -teorizado por economistas como el Nobel Milton Friedman- se ha esfumado: el capitalismo no conduce naturalmente a la democracia; y la libertad económica (entendida como capitalismo) no lleva a la libertad política. Como muestra el caso de China, el capitalismo corporativo casa bien con el autoritarismo político. Igualmente, la lógica capitalista del beneficio y del interés privado ha ido colonizando la lógica democrática de la representatividad y del bien común: frente a la política hecha por lobbies y grupos económicos de presión, el principio democrático «una persona, un voto», según el cual todos los ciudadanos tienen el mismo peso respecto a los problemas comunes, resulta ser una quimera.

La creciente crisis ecológica, así como la gran crisis económica iniciada en 2008, han agudizado la tensión entre capitalismo y democracia. La primera, producida principalmente por el aumento de la explotación capitalista descontrolada de la naturaleza, pone en entredicho las condiciones mismas de existencia de la comunidad política y, muy probablemente, generará turbulencias sociopolíticas de mayor amplitud. Por su parte, la gran crisis económica de los últimos años ha puesto en evidencia la imposibilidad de las élites dirigentes de corregir la creciente desigualdad (Krugman, 2018). La progresiva despolitización de la esfera pública, donde la lógica técnica económica invade más y más esferas de la toma de decisiones, incrementa la percepción de que los representantes 
políticos no son más que unas élites al servicio del capitalismo financiero global, abriéndose aún más la ventana de oportunidad para la respuesta populista que pretende devolver el poder robado al pueblo soberano.

\section{Un interrogante abierto}

Aunque la demanda de re-politizar las decisiones públicas ha encontrado propuestas desde diversas perspectivas teóricas -como, por ejemplo, las republicanas y deliberativas-, es el populismo, a menudo combinado con el nacionalismo y el fundamentalismo religioso, el que ha sido capaz de plantear una narrativa atractiva que apela a porciones significativas de la población. Situar las coordenadas del discurso político en este relato populista ha permitido ocultar la aparente paradoja de que muchos de los líderes y movimientos con trazos populistas provienen de lo que el mismo populismo definiría como élites, e incluso defienden, a menudo, los intereses de las élites económicas. Casos como los

La fuerza del relato populista deviene así un síntoma y una reacción a las continuas crisis de las democracias capitalistas, ante las cuales una porción significativa -cuando no mayoritaria- de la población se siente desposeída y pone en cuestión el sistema vigente.

de Trump, Orbán u otros muestran cómo ello no ha sido obstáculo para apelar exitosamente a un segmento importante de la población que se siente perjudicado o desposeído de sus perspectivas de bienestar, en el contexto de un mundo que se percibe como amenazador, ya sea por la globalización económica, el terrorismo o el fenómeno migratorio. La fuerza del relato populista deviene así un síntoma y una reacción a las continuas crisis de las democracias capitalistas, ante las cuales una porción significativa -cuando no mayoritaria- de la población se siente desposeída y pone en cuestión el sistema vigente ${ }^{30}$.

30. El populismo es líquido: en la sociedad red (Castells, 2004), fluye y se ramifica en formas y combinaciones de todo tipo; toma configuraciones diversas en la dimensión izquierda-derecha, se combina con fuerzas religiosas o seculares, con movimientos nacionalistas o internacionalistas, europeístas o antieuropeístas, enmarcándose en ámbitos regionales o nacionales. Variaciones del relato populista y/o de las estrategias populistas emergen en diferentes contextos culturales, económicos y religiosos, e incluso puede desarrollarse no solo por movimientos emergentes sino en el seno de partidos o instituciones tradicionales. Para la metáfora de la liquidez usada en otros contextos, véase Bauman (2013) y Wagner y Rosich (2017). 
¿Podrían algunas de las fuerzas políticas resultantes del ímpetu populista ser vistas también como un revulsivo que lleve a la reforma de las democracias para reconectar la representación y la participación ciudadana? (Laclau 2005a, 2005b y 2010; Mudde y Rovira Kalterwasser, 2011 y 2018; Mouffe y Errejón, 2015). Nuevos movimientos políticos y sociales se presentan ante la crisis como una alternativa a las élites tradicionales y con programas para renovar las democracias tradicionales a través de nuevos mecanismos de participación, de modo que se reconstruya el vínculo entre representados y representantes a través de nuevos modos más cercanos y permeables a la ciudadanía.

Sin embargo, en el panorama actual, se observa cómo las fuerzas populistasautoritarias son claramente las dominantes y están creciendo a nivel global. Además, un porcentaje preocupante de ciudadanos desconfía cada vez más de la democracia misma como forma de gobierno, incluso entre segmentos de población que se sitúan en el centro del espectro político (Adler, 2018). ¿¿Serán entonces las democracias representativas capaces de adaptarse con éxito ante los retos estructurales y la respuesta populista? Es más, ¿podrán sobrevivir sin inventar nuevos mecanismos económicos mixtos que complementen y moderen las dinámicas capitalistas? Por ahora hay más preguntas que respuestas claras y definitivas. Si esta ola de populismo que recorre el mundo será tan solo una tormenta pasajera o más bien un tsunami que alterará radicalmente las formas de organización política es el gran interrogante abierto de las democracias actuales.

\section{Referencias bibliográficas}

Adler, David. «Centrists are the most hostile to democracy, not extremists». New York Times (23 de mayo de 2018) (en línea) https://www.nytimes.com/interactive/2018/05/23/opinion/international-world/centrists-democracy.html

Akkerman, Agnes; Mudde, Cass y Zaslove, Andrej. «How Populist Are the People? Measuring Populist Attitudes in Voters». Comparative Political Studies, vol. 47, n.o 9 (2014), p. 1.324-1.353. https://doi.org/10.1177/0010414013512600

Arditi, Benjamin. "Populism is hegemony is politics? on Ernesto Laclau's on Populist Reason». Constellations, vol. 17, n. ${ }^{\circ} 3$ (2010), p. 488-497.

Bauman, Zygmunt (2013). Liquid Modernity. Londres: Polity Press.

Bottici, Chiara. A Philosophy of Political Myth. Cambridge: Cambridge University Press, 2010.

Bowman, Paul. "This disagreement is not one: the populisms of Laclau, Rancière and Arditi». Social Semiotics. vol. 17, n. o 4 (2007), p. 539-545.

Canovan, Margaret. Populism. San Diego: Harcourt Brace Jovanovich, 1981. 
Canovan, Margaret. «Two Strategies for the Study of Populism». Political Studies, vol. 30, n.o 4 (1982), p. 544-552. https://doi.org/10.1111/j.1467-9248.1982. tb00559.x

Canovan, Margaret. "Trust the People! Populism and the Two Faces of Democracy». Political Studies, vol. 47, n. ${ }^{\circ} 1$ (1999), p. 2-16. https://doi. org/10.1111/1467-9248.00184

Canovan, Margaret. The people. Cambridge: Polity, 2005.

Castells, Manuel (ed.). The Network Society: A Cross-Cultural Perspective. Northampton, MA: Edward Elgar, 2004.

De la Torre, Carlos. «The resurgence of radical populism in Latin America». Constellations, vol. 14, n. ${ }^{\circ} 3$ (2007), p. 384-397.

De la Torre, Carlos. "In the name of the people: democratization, popular organizations, and populism in Venezuela, Bolivia, and Ecuador». Revista Europea de Estudios Latinoamericanos y del Caribe, vol. 95 (2013), p.: 27-48.

Denton, Derek. Primordial Emotions. The Dawn of Consciousness. Oxford: Oxford University Press, 2006

Dragoman, Dragos y Ungureanu Camil. «The Faces of Populism in PostCommunist Romania». CIDOB Reports (abril de 2017) (en línea) https://www.cidob.org/en/articulos/cidob_report/n1_1/the_faces_of_populism_in_post_communist_romania

Eco, Umberto. "Ur-Fascism». The New York Review of Books (22 de junio de 1995) (en línea) https://www.nybooks.com/articles/1995/06/22/ur-fascism/

Errejón, Íñigo y Serrano, Alfredo. (2011). Ahora es cuando, carajo! Del asalto a la transformación del Estado en Bolivia. Madrid: Viejo Topo, 2011.

Errejón, Ínigo; Mouffe, Chantal y Jones, Owen. Podemos: in the name of the people. Londres: Lawrence \& Wishart, 2016.

Fassin, Eric. Populism. Left and Right. Cambridge: Prickly Paradigm Press, 2018. Freeden, Michael. «Is Nationalism a Distinct Ideology?». Political Studies, vol. 46, n.o 4 (1998), p. 748-765. https://doi.org/10.1111/1467-9248.00165

Girard, René. Violence and the Sacred. Baltimore: The Johns Hopkins University Press, 1977.

Gros, Daniel. «Sex and Populism». Project Syndicate (5 de septiembre de 2018) (en línea) https://www.project-syndicate.org/commentary/migration-fuelssexual-competition-and-populism-by-daniel-gros-2018-09

Hawkins, Kirk; Riding, Scott y Muddle, Cas. «Measuring Populist Attitudes». C\&M Working Paper, n. 55 (2012) (en línea) https://works.bepress.com/ cas_mudde/72/

Iglesias, Pablo. «Understanding Podemos». New Left Review, vol. 93 (mayo-junio de 2015), p. 7-21 (en línea) https://newleftreview.org/II/93/pablo-iglesias-understanding-podemos 
Ionescu, Ghita y Gellner, Ernest. Populism: its meaning and national characteristics. Londres: Macmillan, 1969.

Koselleck, Reinhardt. Critique and Crisis: Enlightenment and the Pathogenesis of Modern Society. Cambridge, Mass.: MIT Press, 1988.

Krugman, Paul. "What's the matter with Europe?». New York Times (21 de mayo de 2018) (en línea) https://www.nytimes.com/2018/05/21/opinion/europeeuro-democracy-wrong.html? rref=collection $\% 2$ Fcolumn $\% 2$ Fpaul-krugman \&action $=$ click\&contentCollection $=$ opinion \& region $=$ stream $\&$ module $=$ stre am_unit\&version=latest\&contentPlacement=3\&pgtype $=$ collection

Laclau, Ernesto. "Towards a theory of populism». Politics and ideology in Marxist theory, vol. 3, n.o 1 (1977), p. 143-200.

Laclau, Ernesto. «Populist rupture and discourse». Screen Education, vol. 34 (1980), p. 87-93.

Laclau, Ernesto. On populist reason. Buenos Aires: Verso, 2005a.

Laclau, Ernesto. «Populism: What's in a Name». En: Panizza, Francisco (ed.). Populism and the Mirror of Democracy. Buenos Aires: Verso, 2005b, p. 32-49.

Laclau, Ernesto. Nuevas reflexiones sobre la revolución de nuestro tiempo. Buenos Aires: Nueva Visión, 2010.

Lakoff, George. Moral politics: How liberals and conservatives think. Chicago: University of Chicago Press, 1996.

LeDoux, Joseph. The Emotional Brain: The Mysterious Underpinnings of Emotional Life. Nueva York: Simon \& Schuster, 1998.

Linz, Juan y Stepan, Alfred. Problems of Democratic Transition and Consolidation: Southern Europe, South America, and Post-Communist Europe. Baltimore y Londres: Johns Hopkins University Press, 1996.

Meyer, Robinson. "The Grim Conclusions of the Largest-Ever Study of Fake News». The Atlantic (8 de marzo de 2018) (en línea) https://www.theatlantic.com/technology/archive/2018/03/largest-study-ever-fake-news-mit-twitter/555104/

Morlino, Leonardo. Democrazia i mutamenti. Roma: Luiss University Press, 2014.

Mouffe, Chantal. «Deliberative Democracy or Agonistic Pluralism?». Social Research, vol. 66, n. 3 (1999), p. 745-758.

Mouffe, Chantal y Errejón, Ínigo . Construir Pueblo. Barcelona: Icaria, 2015.

Mudde, Cass. «The populist zeitgeist». Government and Opposition, vol. 39, n. ${ }^{\circ} 4$ (2004), p. 541-563.

Mudde, Cass. Populist radical right parties in Europe (vol. 22). Cambridge: Cambridge University Press, 2007.

Mudde, Cass y Rovira Kaltwasser, Cristóbal. Populism in Europe and the Americas. Threat or Corrective for Democracy? Nueva York: Cambridge University Press, 2011. 
Mudde, Cass y Rovira Kaltwasser, Cristóbal. «Studying Populism in Comparative Perspective: Reflections on the Contemporary and Future Research Agenda». Comparative Political Studies (26 de julio de 2018) (en línea) http://journals.sagepub.com/doi/abs/10.1177/0010414018789490

Müller, Jan-Werner. What is populism? Londres: Penguin UK, 2017.

Nussbaum, Martha. The Monarchy of Fear. A Philosopher looks at our political crisis. Nueva York: Simon \& Schuster, 2018.

Oakeshott, Michael. The Politics of faith \& the politics of scepticism. New Haven: Yale University Press, 1996.

Panizza, Francisco (ed.). Populism and the Mirror of Democracy. Buenos Aires: Verso, 2005.

Piketty, Thomas. Capital in the XXI Century. Cambridge, Mass.: Belknap Press, Harvard University Press, 2017. 10.1080/13569310701822289.

Polanyi, Karl (20019. The Great Transformation. The Political and Economic Origins of our Time. Beacon Press.

Stanley, Ben (2008). "The thin ideology of populism». Journal of Political Ideologies 13 (1): 95-110. doi:

Stokes, Bruce. "Populist views in Europe: It's not just the economy». Pew Research Center, 19 de julio de 2018 (en línea) http://www.pewresearch. org/fact-tank/2018/07/19/populist-views-in-europe-its-not-just-the-economy/

Tipaldou, Sophia y Uba, Ktrin. «Movement dynamics in dissimilar settings: The far right in Greece and Russia». European Societies (2018, en prensa).

Ungureanu, Camil y Monti, Paolo. Contemporary Political Philosophy and Religion: between Public Reason and Pluralism. Londres: Routledge, 2018.

Ungureanu Camil y Dumitru, Speranta. Populism, political emotions, and public swearing: the Romanian case. Manuscrito, 2018

Vallespín, Fernando y Martínez-Bascuñán, Máriam. Populismos. Madrid: Alianza Editorial, 2017.

Vosoughi, Soroush; Roy, Deb y Aral, Sinai. "The spread of true and false news online». Science, vol. 359, n. ${ }^{\circ} 6.380$ (2018), p. 1.146-1.151 (en línea) http://science.sciencemag.org/content/359/6380/1146

Wagner, Peter y Rosich, Gerard (eds.). The trouble with democracy. Edimburgo: Edinburgh University Press, 2018.

Walzer, Michael. Politics and Passion. Towards a more egalitarian liberalism. New Haven: Yale University Press, 2005.

Wiles, Peter. «A syndrome, not a doctrine: Some elementary theses on populism». En: Ionescu, Ghita y Gellner, Ernest (eds.). Populism: Its meaning and national characteristics. Londres: Macmillan, 1969, p. 166-179. 


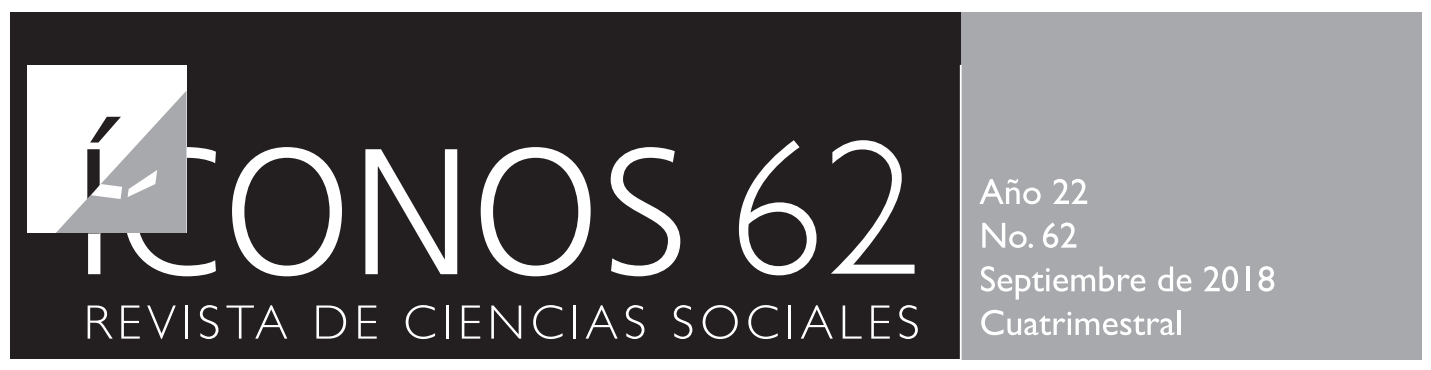

Economía popular: entre la informalidad y la reproducción ampliada

Presentación del dossier

Verónica Gago, Cristina Cielo y Francisco Gachet

Más allá de la precariedad: prácticas colectivas y subjetividades políticas desde la economía popular argentina

María Inés Fernández Álvarez

Formalización de las organizaciones de recicladores de oficio en Bogotá: reflexiones desde la economía popular

Luisa Fernanda Tovar

Políticas de promoción de la economía social en Argentina: una aproximación desde los saberes expertos

Eliana Lijterman

La configuración del trabajo en el siglo XXI: el mercado Eloy Salmón y los movimientos moleculares del capital

María Luisa López Guerrero

Experiencias de mujeres en tianguis y mercados populares en Oaxaca

Nallely Guadalupe Tello Méndez

¡Costureros carajo! Trayectorias de lucha y autogestión en las economías populares argentinas

Alioscia Castronovo

El trabajo político desde una perspectiva cualitativa: aporte para el análisis de las subjetividades

Mauricio Bustamante Fajardo

La productividad de la contingencia en economías populares del sur global.

Diálogo con AbdouMaliq Simone

Cristina Cielo

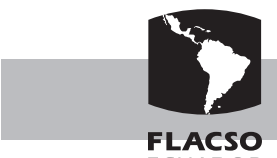

Revista de la Facultad Latinoamericana de Ciencias Sociales - Sede Ecuador
Religión, fiesta y trabajo: características de la migración boliviana en São Paulo

Eduardo Schwartzberg Arteaga

$\backsim$ Reparación a víctimas de violación de derechos humanos y crímenes de lesa humanidad en Ecuador María Cristina Solís Chiriboga

Apuntes para pensar una ecología política de los territorios fronterizos Martha Moncada Paredes

Salidas del laberinto capitalista. Decrecimiento y postextractivismo de Alberto Acosta y Ulrich Brand Héctor Rubén LópezTerán

La planificación estatal en el interjuego entre desarrollo y democracia de Patricio Moncayo Lautaro Ojeda Segovia

Resignificar la educación: comunicación, cultura y pedagogía(s)

de Jorge Daniel Vásquez

José Alberto Flores Jácome

Número anterior:

\section{ICONOS 6I: Geografías críticas en América Latina}

Número siguiente:

ICONOS 63:Trabajo y nuevas configuraciones de clase en América Latina.

Íconos. Revista de Ciencias Sociales está incluida en los siguientes índices cientificos: Academic Search Premier; Directory of Publishing Opportunities (CABELL'S); Clasificación Integrada de Revistas Científicas (CIRC); Citas Latinoamericanas en Ciencias Sociales (CLASE); DIALNET; Directory of Open Access Journal (DOA)): Emerging Source Citation Index (ESCl) Web of Science; FLACSO Andes; Fuente Académica Plus; Hispanic American Periodical Index (HAPI): International Bibliography of the Social Science (IBSS): Informe Académico Thompson Gale; International Institute of Organized Research (I2OR); LatAm-Studies, LATINDEX- catálogo; MIAR; Political Science Complete; REDALYC; REDIB; SciELO Ecuador; Sociological Abstracts; Social Science Jornals. Sociology Collection; Ulrich's Periodical Directory; Worldwide Political Science Abstracts (WPSA).

Página web: wuw.revistaiconos.ec

Correo electrónico: revistaiconos@flacso.edu.ec 